\title{
Pengaruh Pemanfaatan Aplikasi Digital Terhadap Pemberdayaan UMKM di Kabupaten Kutai Timur
}

\author{
Muhamad Yazid Bustomi ${ }^{1}$, Nani Rohaeni ${ }^{2}$, Dhani Aryanto ${ }^{3}$, Faizal $^{4}$ \\ 1,2,3 Sekolah Tinggi Pertanian Kutai Timur \\ Jl.Soekarno-Hatta, Sangatta Utara, Kutai Timur, Kalimantan Timur \\ ${ }^{4}$ Community Empowerment dept,. PT. Kaltim Prima Coal \\ e-mail: ${ }^{1}$ myazid.bustomi@ stiperkutim.ac.id. ${ }^{2}$ nanirohaeni@stiperkutim.ac.id \\ ${ }^{3}$ dhaniaryanto@stiperkutim.ac.id, ${ }^{4}$ faizal@kpc.co.id
}

\begin{abstract}
Abstrak
Tujuan dalam penelitian ini adalah (1) mengetahui dampak sosial, ekonomi, dan lingkungan bagi UMKM Mitra setelah menggunakan aplikasi digital, (2) mengidentifikasi pengaruh dampak pemanfaatan aplikasi digital terhadap pemberdayaan UMKM Mitra. Teknik penentuan sampel yang digunakan adalah sampling jenuh yaitu semua anggota UMKM mitra yan telah menggunakan aplikasi digital pada usahanya dijadikan sebagai sampel dalam penelitian ini. Metode analisis data yang digunakan adalah analisis statistik deskriptif melalui program SPSS, dan analisis SEM-PLS dengan bantuan software SmartPLS versi 3.0. Hasil penelitian menunjukkan bahwa nilai rerata statistik deskriptif tertinggi pada dampak ekonomi dengan nilai 3,94 dan standar deviasi 0,70. Hal ini menunjukkan bahwa pemanfaatan aplikasi digital memberikan dampak secara ekonomi bagi UMKM Mitra CDO PT. KPC. Variabel (dampak) dari pemanfaatan aplikasi digital yang berpengaruh signifikan terhadap pemberdayaan UMKM Mitra adalah dampak ekonomi dan dampak sosial, sedangkan dampak lingkungan tidak berpengaruh signifikan terhadap pemberdayaan UMKM Mitra.
\end{abstract}

Kata Kunci: Aplikasi Digital, Pemberdayaan UMKM, Partial Least Square

\begin{abstract}
The objectives of this study were (1) to determine the social, economic, and environmental impacts of MSMEs Partners after using digital applications (2) to identify the effects of the utilization digital applications on the empowerment of MSMEs Partners. The sampling technique used saturated sampling, where all members of the MSMEs partners who had used digital applications in their business were used as samples in this research. The data analysis method was descriptive statistics with SPSS program, and SEM-PLS with the SmartPLS version 3.0 software. The results showed that the highest mean value of descriptive statistics was the economic impact with a value of 3.94 and a standard deviation of 0.70. It stated the utilization of digital applications has an economic impact on MSMEs Partners Community Development Officier PT. KPC. The variables (impact) of the utilization digital applications that have a significant effects on the empowerment of MSMEs Partners are economic impacts and social impacts, while environmental impacts do not have a significant effect on the empowerment of MSMEs Partners.
\end{abstract}

Keywords: Digital Applications, Empowerment MSMEs, Partial Least Square.

\section{Pendahuluan}

Kegiatan usaha skala mikro, kecil, dan menengah (UMKM) yang tumbuh di masyarakat memiliki kontribusi yang besar dalam perekonomian Indonesia. Pada tahun 2018, UMKM berkontribusi terhadap produk domestik bruto (PDB) Indonesia sebesar 60,3\% dengan jumlah 64,2 juta unit usaha serta mampu menyerap $97 \%$ dari total tenaga kerja (Databoks, 2020). Sementara, Rahadhini (2012) menjelaskan UMKM yang tangguh dan tersebar di seluruh penjuru tanah air merupakan modal untuk memelihara dan mempertahankan persatuan dan kesatuan bangsa.

Pemberdayaan UMKM menurut UndangUndang Nomor 20 Tahun 2008 tentang Usaha Mikro, Kecil, dan Menengah yaitu suatu upaya yang dilakukan Pemerintah, Pemerintah Daerah, Dunia Usaha, dan masyarakat secara sinergis dalam bentuk penumbuhan iklim dan pengembangan usaha sehingga mampu tumbuh dan berkembang menjadi usaha yang tangguh dan mandiri.

Pada penelitian Suprihadi et al., (2016) dijelaskan bahwa para pelaku UMKM dapat 
meningkatkan daya saingnya dengan beberapa cara, yaitu memperluas jaringan pemasaran, meningkatkan kemampuan dalam penguasaan teknologi informasi dan komunikasi. Slamet et al., (2017) menjelaskan bahwa pemerintah telah berupaya meningkatkan akses dan transfer teknologi untuk mengembangkan pelaku UMKM yang inovatif antara lain dengan pemanfaatan teknologi informasi dan komunikasi agar dapat bersaing.

Sunariani et al., (2017) menjelaskan esensi dari pemberdayaan ekonomi kerakyatan adalah memberdayakan UMKM, koperasi, dan kelompok masyarakat agar mandiri di bidang ekonomi, sehingga mampu membangun kegiatan yang ekonomi produktif. Kurniawan \& Fauziah (2014), terdapat faktor pendukung dalam keberhasilan proses pemberdayaan UMKM, antara lain faktor sumber daya manusia yang memadai, bahan baku yang mudah ditemukan, modal usaha yang ringan, dan dukungan aparatur desa.

Community development officier (CDO) PT KPC sebagai bagian dalam program CSR perusahaan melakukan program pemberdayaan masyarakat dengan cara sosialisasi dan edukasi kepada UMKM Mitra akan pentingnya penggunaan aplikasi digital untuk kemudahan proses administrasi usaha yang dijalankan. Program tersebut diharapkan dapat membantu UMKM Mitra dalam mengelola usahanya. Selain itu, dengan adanya program tersebut diharapkan dapat membatu pemerintah dan mendorong pertumbuhan UMKM sebagai salah satu penggerak roda perekonomian negara yang diwujudkan dengan bertambahnya penciptakan produk dalam negeri untuk kemakmuran suatu negara.

Purwana et al., (2017) menyebutkan bahwa dunia digital diprediksi akan menjadi poin penting bagi seluruh aktivitas manusia, termasuk aktivitas bisnis bagi UMKM. Barus et al., (2020) menyatakan bahwa UMKM sebaiknya dapat berdampingan dengan teknologi agar dapat beradaptasi dengan perkembangan industri di era 4.0. Selain itu, Amelia et al., (2017) menjelaskan bahwa, diperlukan strategi khusus dalam upaya peningkatan daya saing UMKM dengan cara pemanfaatan teknologi informasi dan komunikasi untuk menghadapi persaingan usaha yang semakin ketat. Pelaku UMKM diharapkan dapat memanfaatkan teknologi seluas-luasnya agar usaha cepat maju dan berkembang.

Lubis \& Junaidi (2016) menjelaskan dalam penelitiannya bahwa untuk dapat meningkatkan daya saingnya, UMKM dituntut melakukan perubahan agar dapat terus berjalan dan berkembang yaitu dengan cara memanfaatkan teknologi informasi (TI). Perkembangan teknologi dan informasi yang begitu pesat membawa dampak bagi kehidupan manusia terutama dunia usaha. Perkembangan beberapa Aplikasi di Indonesia yang telah banyak dipergunakan dalam pengelolaan keuangan akuntansi keuangan salah satunya adalah aplikasi edukasi sistem pencatatan keuangan digital Qasir.

Aplikasi qasir pada smartphone berbasis android adalah aplikasi startup point of sales (POS) dagang gratis yang memberikan kemudahan dalam pencatatan penjualan, pengelolaan stok barang, pencatatan pemasukan dan pengeluaran dengan lebih cepat serta dapat memantau transaksi secara jarak jauh dengan desain tampilan yang mudah dipahami oleh UMKM. Berkaitan dengan penggunaan pelaporan keuangan berbasis aplikasi qasir terdapat dampak (implikasi) yang terjadi pada aspek sosial, ekonomi maupun lingkungan bagi pada pelaku UMKM maupun customer usaha tersebut. Besaran dampak yang terjadi dapat terukur dalam bentuk data kualitatif melalui persepsi dari UMKM. Berdasarkan hal tersebut, maka dilakukan penelitian ini dengan tema analisis dampak dan pengaruh pemnafaatan aplikasi digital terhadap pemberdayaan UMKM Mitra CDO PT. KPC di Kabupaten Kutai Timur.

\section{Metode Penelitian}

Penelitian ini dilakukan pada beberapa kecamatan di Kabupaten Kutai Timur, yaitu Kecamatan Sangatta Utara, Sangatta Selatan, Kaliorang, dan Bengalon. Kecamatan tersebut merupakan lokasi usaha dari UMKM Mitra CDO PT KPC. Populasi dalam penelitian ini adalah seluruh anggota UMKM Tangguh Batch II mitra CDO PT KPC yang berjumlah 24 UMKM. Berdasarkan jumlah tersebut diketahui bahwa tidak semua UMKM Mitra menerapkan aplikasi qasir pada usahanya, terdapat 19 UMKM yang telah menerapkan aplikasi qasir pada usahanya.

Teknik penentuan sampel yang digunakan yaitu sampling jenuh. Menurut Sugiyono, (2014) teknik sampling jenuh digunakan jika semua anggota populasi digunakan sebagai sampel, hal tersebut karena jumlah populsi relatif kecil kurang dari 30, maka semua UMKM Mitra yang telah menerapkan aplikasi qasir digunakan sebagai sampel dalam penelitian ini. Data yang diperlukan dalam penelitian adalah data primer dan data sekunder. Data Primer diperoleh langsung dari lapangan, sesuai dengan keadaan yang sebenarnya melalui observasi, wawancara dan kuisioner. Data sekunder diperoleh melalui studi kepustakaan.

Gambaran singkat penelitian dapat dilihat pada Gambar 1. 


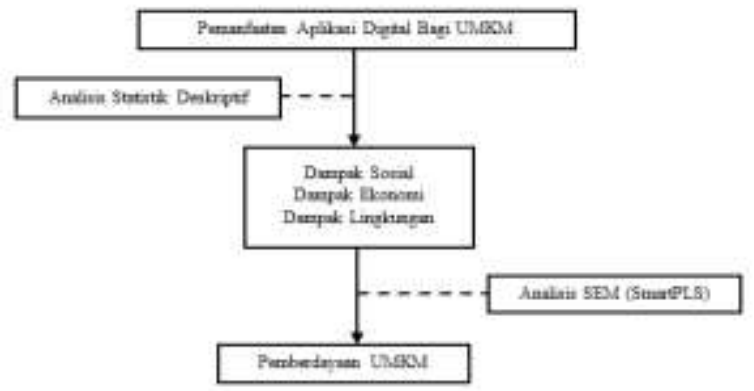

Gambar 1. Kerangka Pemikiran Penelitian

Metode analisis daya yang digunakan terdiri dari sebagai berikut:

1. Analisis Statistik Deskriptif

Program pemanfaatan aplikasi digital untuk UMKM Mitra PT KPC merupakan bagian dari kegiatan pemberdayaan masyarakat yang memberikan dampak sosial, ekonomi, dan lingkungan sebagaimana penelitian Satori et al., (2017) bahwa pilar program pemberdayaan masyarakat atau CSR terdiri dari pendidikan, kesehatan, ekonomi, sosial budaya, dan lingkungan. Pada penelitian ini dilakukan analisis terkait dampak sosial, ekonomi, dan lingkungan pada UMKM mitra sesudah menggunakan aplikasi digital qasir menggunakan analisis statistik deskriptif melalui software SPSS (Statistical Product and Service Solutions).

Statistik deskriptif digunakan untuk menentukan dampak pemanfaatan aplikasi qasir melalui nilai rerata skor dan standar deviasi dari total skor yang diperoleh pada saat wawancara kepada responden terpilih menggunakan pernyataan yang ada di kuesioner. Setiap dampak yang ingin diketahui baik sosial, ekonomi, maupun lingkungan akan dibuat beberapa pernyataan-pernyataan yang menggambarkan dampak yang dihasilkan dari adanya program tersebut sesudah menggunakan aplikasi qasir. Langkah selanjutnya adalah dilakukan skoring pernyataan berdasarkan respon dan persepsi dari jawaban responden terhadap pernyataan yang diajukan. Penentuan skor dalam kuesioner menggunakan skala likert, yaitu skala yang berisi lima tingkat preferensi jawaban (sangat tidak setuju, tidak setuju, cukup setuju, setuju, dan sangat setuju) dalam kuesioner yang bersifat tertutup.

\section{Analsis SEM-PLS}

Untuk mengetahui besarnya pengaruh pemanfaatan aplikasi qasir terhadap pemberdayaan UMKM Mitra dianalisis menggunakan SEM-PLS (Structural Equation Modeling-Partial Least Square). Tahapan pada analisis PLS yang pertama adalah membuat kontruksi diagram jalur. Pada konstruksi diagram menggambarkan hubungan atau jalur antara instrumen penelitian (variabel manifest) terhadap variabel laten yang disebut model pengukuran (outer model) serta hubungan antara variabel laten eksogen terhadap variabel laten eksogen atau yang disebut model structural (inner model). Pada penelitian ini variabel laten eksogen terdiri dari Dampak Sosial $\left(\mathrm{X}_{1}\right)$, Dampak Ekonomi $\left(\mathrm{X}_{2}\right)$, dan Dampak Lingkungan $\left(\mathrm{X}_{3}\right)$, sedangkan variabel laten endogennya adalah pemberdayaan UMKM $\left(\mathrm{Y}_{1}\right)$. Gambar 2. merupakan model konstruk analisis PLS yang digunakan pada penelitian ini.

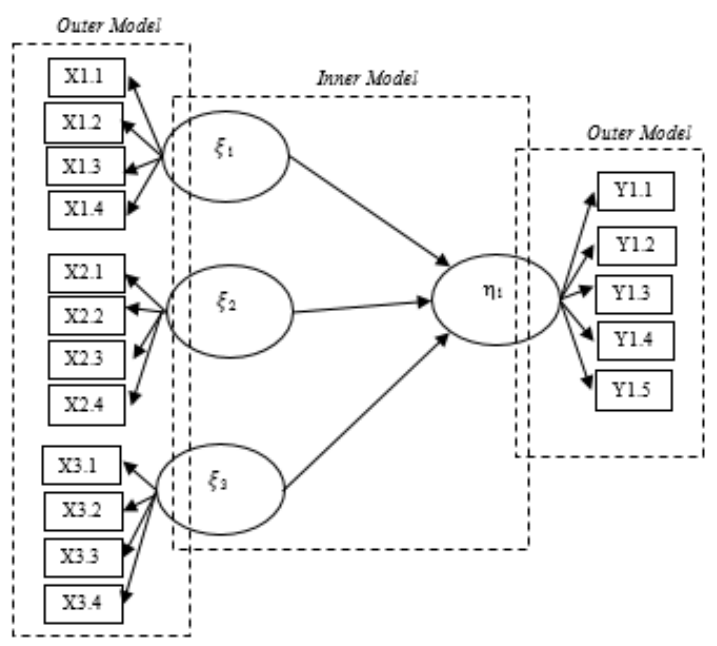

Gambar 2. Model konstruk analisis PLS

Deskripsi Variabel Manifest

Dampak Sosial (X1)

X1.1. : Pada aplikasi qasir UMKM dapat menambah, mengatur, dan menghapus data produk

X1.2. : Aplikasi qasir memberi kemudahan untuk melakukan pencatatan keuangan dalam usaha yang dijalankan

X1.3. : Perhitungan stok barang lebih mudah karena ada barcode produk di aplikasi qasir

X1.4. : Tersedia database pelanggan, sehingga promosi lebih mudah dilakukan

Dampak Ekonomi (X2)

X2.1. : Data penjualan dan pembelian tercatat dengan teratur di aplikasi qasir

X2.2. : Proses administrasi lebih efisien (hemat waktu)

X2.3. : Data untuk membuat laporan keuangan tersimpan di aplikasi qasir

X2.4. : Aplikasi qasir tidak berbayar

Dampak Lingkungan (X3)

X3.1. : Penggunaan kertas (buku kas, nota) menjadi berkurang bahkan tidak digunakan

X3.2. : Pemakaian BBM untuk membayar tagihan bulanan menjadi berkurang

X3.3. : Aplikasi qasir dapat membantu 


\begin{tabular}{|c|c|}
\hline \multirow[b]{2}{*}{ X3.4. } & roduk \\
\hline & $\begin{array}{l}\text { : Pengelolaan pelanggan menjadi } \\
\text { lebih mudah karena ada database } \\
\text { pelanggan }\end{array}$ \\
\hline \multicolumn{2}{|c|}{ Kemandirian UKM (Y1) } \\
\hline Y1.1. & $\begin{array}{l}\text { : Pencatatan keuangan menjadi lebih } \\
\text { teratur dan akurat }\end{array}$ \\
\hline Y1.2. & $\begin{array}{l}\text { : Data stok (persediaan barang) } \\
\text { dalam usaha selalu tersedia }\end{array}$ \\
\hline Y1.3. & $\begin{array}{l}: \text { Laporan keuangan menjadi lebih } \\
\text { transparan dan mudah dipahami }\end{array}$ \\
\hline Y1.4. & $\begin{array}{l}\text { : Manajemen usaha lebih modern } \\
\text { karena memanfaatkan teknologi }\end{array}$ \\
\hline \multirow[t]{2}{*}{ Y1.5. } & : Pengelolaan \\
\hline & $\begin{array}{l}\text { lingkungan karena } m \\
\text { penggunaan kertas dan } \mathrm{A}^{\prime}\end{array}$ \\
\hline
\end{tabular}

Tahapan selanjutnya adalah evaluasi model PLS yang terdiri dari outer model dan inner model.

\section{Outer Model Evaluation}

Pada evaluasi model pengukuran dilakukan melalui uji discriminant validity. Uji validitas discriminant berhubungan dengan prinsip bahwa instrumen pengukur yang berbeda seharusnya tidak berkorelasi tinggi dengan cara melihat nilai loading factor yang harus lebih besar dari batas minimal yaitu 0,6 (Ghozali \& Latan, 2015). Selain itu, evaluasi model pengukuran dilakukan dengan uji reliabilitas konstruk untuk membuktikan akurasi, konsistensi, dan ketepatan instrumen dalam mengukur model konstruk dengan melihat nilai composite reliability yang harus lebih besar dari 0,7 .

\section{Inner Model Evaluation}

Evaluasi model struktural dilakukan dengan cara melihat nilai $R$-squares dan nilai koefisein jalur yang ada di dalam konstruk. Perubahan nilai $R$-squares dapat digunakan untuk menjelaskan pengaruh variabel laten eksogen terhadap variabel laten endogen, apakah memiliki pengaruh yang substantive atau tidak. Kriteria $R$-squares diklasifikaskan ke dalam model kuat ( $\mathrm{R} 2 \geq 0,67)$, moderate atau sedang $(0,67>\mathrm{R} 2 \geq 0,33)$, dan lemah $(0,33>R 2 \geq 0,19)$ (Ghozali \& Latan, 2015). Sementara itu, uji signifikansi dilakukan untuk mengetahui pengaruh koefisien jalur dari variabel laten eksogen terhadap laten endogen dilakukan dengan membandingkan nilai t-statistic pada hasil olah data bootstraping SmartPLS terhadap nilai ttabel pada tingkat kesalahan $(\alpha=1 \%$, t-tabel $=2,95)$, $(\alpha=5 \%$, t-tabel $=2,13)$, dan $(\alpha=10 \%$, t-tabel $=1,75)$. Jika nilai t-statistik setiap jalur lebih kecil dariapada salah satu nilai t-tabel tersebut maka dapat disimpulkan bahwa jalur tersebut tidak signifikan.

\section{Hasil dan Pembahasan}

Statistik Deskriptif Dampak Sosial, Ekonomi dan Lingkungan
Penilaian dampak dari pemanfaatan aplikasi digital dilakukan menggunakan analisis statistif deskriptif dengan bantuan program SPSS. Dampak yang diukur terlebih dahulu dibuat pernyataanpernyataan untuk dijawab oleh penerima manfaat dalam hal ini UMKM mitra berdasarkan pengalamannya menggunakan aplikasi qasir. Penentuan skor penilaian dalam kuesioner menggunakan skala likert, yaitu skala yang berisi lima tingkat preferensi jawaban yaitu 1 untuk sangat tidak setuju, 2 untuk tidak setuju, 3 untuk cukup setuju, 4 yang berati setuju, dan 5 yang berarti sangat setuju) dalam kuesioner yang bersifat tertutup. Pada Tabel 1,2,3 merupakan hasil statistik deskriptif program SPSS berdasarkan kuesioner yang telah diisi responden dalam hal ini UMKM Mitra.

Tabel 1. Statistik Deskriptif Dampak Sosial Setelah Menggunakan Aplikasi

\begin{tabular}{|c|c|c|}
\hline Pernyataan & Rerata & $\begin{array}{l}\text { Standar } \\
\text { Deviasi }\end{array}$ \\
\hline $\begin{array}{l}\text { UMKM memahami } \\
\text { pengoperasian aplikasi qasir }\end{array}$ & 3,53 & 1,02 \\
\hline $\begin{array}{l}\text { Telah menerapkan aplikasi qasir } \\
\text { untuk transaksi usaha yang } \\
\text { terjadi }\end{array}$ & 3,74 & 0,81 \\
\hline $\begin{array}{l}\text { Pengelolaan dan pembaruan data } \\
\text { stok barang dilakukan melalui } \\
\text { aplikasi qasir }\end{array}$ & 3,53 & 0,96 \\
\hline $\begin{array}{l}\text { Memiliki data } \quad \text { (database) } \\
\text { pelanggan }\end{array}$ & 3,53 & 1,02 \\
\hline $\begin{array}{l}\text { Aplikasi qasir penting untuk } \\
\text { digunakan pada usaha yang } \\
\text { dijalankan }\end{array}$ & 4,21 & 0,63 \\
\hline Dampak Sosial & 3,71 & 0,71 \\
\hline
\end{tabular}

Sumber: Data Primer, 2020

Pada Tabel 1. diketahui bahwa dampak sosial setelah menggunakan aplikasi qasir yaitu UMKM pemerima manfaat merasa bahwa aplikasi digital tersebut penting untuk digunakan dalam usaha yang dijalankan dengan nilai rerata 4,21 dan standar deviasi 0,63. Nilai standar deviasi yang lebih besar daripada nol menunjukkan bahwa jawaban responden variatif, semakin tinggi nilai standar deviasi berarti jawaban responden semakin variatif (tidak homogen). Pada pernyataan tersebut sebanyak 57,9\% atau 11 orang setuju dan 6 orang sangat setuju jika apliaksi digital penting untuk digunakan pada era globalisasi saat ini. Hal tersebut dapat menggambarkan bahwa sebagian besar UMKM ingin beralih dari pencatatan keuangan secara tradisional kepada pencatatan secara digital melaluli aplikasi yang mudah digunakan. Sementara pada pernyataan keempat, menunjukkan bahwa sebanyak $57,9 \%$ responden setuju jika dengan aplikasi qasir dapat memiliki database pelanggan. 
Tabel 2. Statistik Deskriptif Dampak Ekonomi Setelah Menggunakan Aplikasi

\begin{tabular}{lcc}
\multicolumn{1}{c}{ Pernyataan } & Rerata & $\begin{array}{l}\text { Standar } \\
\text { Deviasi }\end{array}$ \\
\hline $\begin{array}{l}\text { Tidak ada biaya untuk } \\
\text { pembelian buku kas, nota dan }\end{array}$ & 3,79 & 0,92 \\
ATK & & \\
$\begin{array}{l}\text { Aplikasi qasir tidak berbayar } \\
\text { atau gratis }\end{array}$ & 4,05 & 0,78 \\
$\begin{array}{l}\text { Nota transaksi dapat dikirim } \\
\text { secara online ke pelanggan }\end{array}$ & 4,11 & 0,94 \\
$\begin{array}{l}\text { Biaya kurir ditanggung } \\
\text { konsumen sehingga tidak ada } \\
\text { biaya untuk BBM }\end{array}$ & 3,84 & 0,76 \\
\hline \multicolumn{1}{c}{ Dampak Ekonomi } & 3,94 & 0,70 \\
\hline
\end{tabular}

Kelebihan aplikasi qasir selain tidak berbayar, aplikasi ini juga dapat mengirim nota secara online ke pelanggan sehingga mampu menghemat kertas untuk nota pembelian. Pernyataan tersebut memiliki nilai rata-rata 4,11 dan standar deviasi 0,94 atau sebanyak 9 orang setuju dan 7 orang sangat setuju jika aplikasi qasir memudahkan pengiriman nota kepada pelanggan jika melakukan delivery order.

Sementara itu, aplikasi qasir dapat dimiliki gratis tanpa harus membayar tagihan setiap bulannya, hal ini dibuktikan dengan jawaban responden yang menunjukkan setuju dengan pernyataan tersebut. Aplikasi qasir juga memberikan dampak secara ekonomi yaitu berkurangnya biaya untuk membeli buku, nota, dan ATK yang digunakan untuk pencatatan secara manual dengan nilai rerata jawaban responden 3,79 dan standar deviasi 0,92 .

Tabel 3. Statistik Deskriptif Dampak Lingkungan Setelah Menggunakan Aplikasi

\begin{tabular}{|c|c|c|}
\hline Pernyataan & Rerata & $\begin{array}{l}\text { Standar } \\
\text { Deviasi }\end{array}$ \\
\hline $\begin{array}{l}\text { Tidak menggunakan } \\
\text { buku, ATK }\end{array}$ & 3,68 & 0,75 \\
\hline $\begin{array}{lrr}\text { Konsumsi } & \text { BBM } & \text { untuk } \\
\text { membayar } & \text { tagihan dan } \\
\text { operasional } & \text { kendaraan } \\
\text { berkurang } & & \end{array}$ & 3,68 & 0,75 \\
\hline $\begin{array}{l}\text { Lebih mudah mengelola } \\
\text { pelanggan melalui aplikasi } \\
\text { qasir }\end{array}$ & 3,63 & 0,68 \\
\hline Dampak Lingkungan & 3,67 & 0,50 \\
\hline
\end{tabular}

Sumber: Data Primer, 2020

Pada Tabel 3. nenunjukkan bahwa dengan adanya aplikasi qasir mampu mengurangi penggunaan kertas, buku untuk pencatatan keuangan usaha, sehingga dapat mengurangi penggunaan bahan baku untuk pembuatan kertas yang secara tidak langsung juga berdampak pada lingkungan menjadi lebih bersih. Pada pernyataan tersebut sebanyak $10(52,6 \%)$ responden setuju, 2 lainnya sangat setuju, serta $6(31,6 \%)$ di antaranya cukup setuju. Selain pernyataan tersebut, pada aplikasi qasir juga memudahkan pemilik usaha untuk mengelola pelanggan sebanyak $57,9 \%$ responden setuju dan 5,3\% responden sangat setuju dengan pernyataan tersebut.

\section{Hasil Analisis PLS}

Evaluasi model konstruk dilihat melalui uji PLS Algorithm pada software SmartPLS dengan cara eliminasi terhadap variabel manifest dengan nilai loading factor di atas 0.6 sehingga telah memenuhi batas minumum. Pada gambar 3. terlihat hasil uji PLS Algorithm berikut ini.

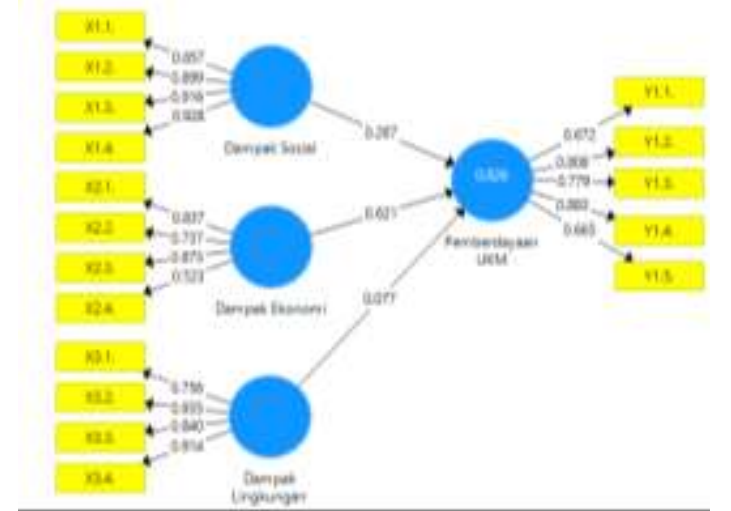

Gambar 3. Hasil Kontruksi Diagram Jalur Uji PLS Algoritm Tahap 1.

Pada evaluasi kontruksi diagram jalur di atas diketahui bahwa terdapat 3 variabel manifest dieliminasi karena nilai loading factor belum mencapai batas minimum yaitu X2.4, Y1.1, dan Y1.5. Setelah dilakukan eliminasi pada 3 variabel manifest tersebut kemudian didapatkan model yang loading factor yang melebihi batas minimum dan dinyatakan valid untuk digunakan sebagai instrumen penelitian sebagaimana tampak pada Gambar 4. di bawah ini.

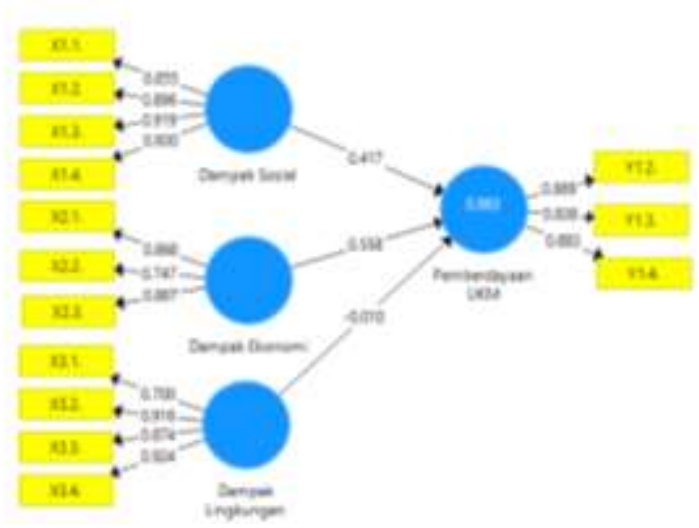

Gambar 4. Kontruksi Diagram Jalur Tahap Akhir Setelah Eliminasi

\section{Uji Discriminant Validity}

Evaluasi model pengukuran dilakukan dengan validitas convergent melaui nilai 
Standardized Loading Factor yang menunjukkan besarnya korelasi antara item pernyataan yang digunakan terhadap konstruknya. Pada Tabel 4. Berikut ini menggambarkan nilai loading factor untuk setiap indikator lebih besar 0,6 serta berada di atas batas minimum. Hal ini sesuai dengan Ghozali \& Latan (2015) yang menyatakan bahwa indiaktor yang nilai loading factor di atas 0,6 maka dinyatakan valid.

Tabel 4. Uji Validitas Berdasarkan nilai Standardized Loading Factor

\begin{tabular}{cccc}
\hline $\begin{array}{c}\text { Variabel } \\
\text { Manifest }\end{array}$ & $\begin{array}{c}\text { Loading } \\
\text { factor }\end{array}$ & t-statistic & Ket \\
\hline X1.1. & 0,855 & 9,109 & Valid \\
X1.2. & 0,896 & 20,247 & Valid \\
X1.3. & 0,919 & 19,445 & Valid \\
X1.4. & 0,930 & 28,060 & Valid \\
X2.1. & 0,868 & 7,670 & Valid \\
X2.2. & 0,747 & 6,634 & Valid \\
X2.3. & 0,967 & 6,886 & Valid \\
X3.1. & 0,700 & 2,679 & Valid \\
X3.2. & 0,916 & 7,483 & Valid \\
X3.4. & 0,874 & 11,717 & Valid \\
X3.4. & 0,924 & 7,922 & Valid \\
Y1.2. & 0,869 & 14,565 & Valid \\
Y1.3. & 0,838 & 10,176 & Valid \\
Y1.4. & 0,883 & 7,991 & Valid \\
\hline
\end{tabular}

Sumber: Data Primer, 2020

Uji Composite Reability

Tabel 5. Uji Reliabilitas Berdasarkan Nilai Composite Reability

\begin{tabular}{lcc}
\multicolumn{3}{c}{ Composite Reability } \\
\hline & $\begin{array}{c}\text { Composite } \\
\text { Reability }\end{array}$ & Ket \\
\hline Dampak Sosial & 0,868 & Reliabel \\
Dampak Ekonomi & 0,917 & Reliabel \\
Dampak Lingkungan & 0,945 & Reliabel \\
Pemberdayaan UKM & 0,898 & Reliabel \\
\hline
\end{tabular}

Sumber: Data Primer, 2020

Berdasarkan hasil uji PLS-Algorithm menunjukkan bahwa nilai composite reliability untuk semua variabel laten lebih besar dari 0,7 yaitu sesuai dengan pendapat Ghozali \& Latan (2015) yang menjelaskan bahwa instrumen yang digunakan dalam setiap variabel laten sudah reliabel.

Tabel 6. Inner Model dilihat dari Nilai R-square

\begin{tabular}{lcll}
\multicolumn{1}{c}{$\begin{array}{l}\text { Variabel } \\
\text { Laten }\end{array}$} & $\begin{array}{c}R \text { - } \\
\text { square }\end{array}$ & $\begin{array}{l}\text { Adj } R \text { - } \\
\text { square }\end{array}$ & Ket \\
\hline $\begin{array}{l}\text { Pemberdayaan } \\
\text { UKM }\end{array}$ & 0,863 & 0,835 & Kuat \\
\hline
\end{tabular}

Sumber: Data Primer, 2020

Pada Tabel 6. di atas menunjukan hasil evaluasi model struktural (Inner Model) dengan melihat nilai $R$-square yang menjelaskan besarnya persentase variabel laten eksongen mampu menjelaskan variabel laten endogen. Kriteria $R$ - squares menurut Ghozali \& Latan (2015) diklasifikaskan menjadi 3 kategori, yaitu model kuat $\left(R^{2} \geq 0,67\right)$, moderate atau sedang $\left(0,67>R^{2}\right.$ $\geq 0,33)$, dan lemah $\left(0,33>R^{2} \geq 0,19\right)$. Nilai $R$ square variabel pemberdayaan UMKM sebesar 0,863 yaitu berada di antara $\left(R^{2} \geq 0,67\right)$, yang tergolong kategori kuat serta dapat diartikan bahwa sebesar $86,3 \%$ variasi variabel pemberdayaan UMKM dapat dijelaskan oleh variabel dampak sosial, dampak ekonomi, dan dampak lingkungan.

Pengujian Hipotesis

Uji hipotesis dilakukan dengan melihat hasil analisis bootstraping PLS pada Tabel 7. di bawah ini. Jika nilai t-statisistik lebih besar dari t-tabel yang sudah ditentukan maka dapat disimpulkan bahwa jalur tersebut berpengaruh (signifikan).

Tabel 7. Nilai Koefisien Jalur dan Uji Signifikansi Model

\begin{tabular}{lcr}
\hline \multicolumn{1}{c}{ Keterangan } & $\begin{array}{c}\text { Koefisien } \\
\text { Jalur }\end{array}$ & t-statistic \\
\hline $\begin{array}{l}\text { Dampak Sosial } \rightarrow \\
\text { Pemberdayaan UMKM }\end{array}$ & $0,417^{*}$ & 2,100 \\
$\begin{array}{l}\text { Dampak Ekonomi } \rightarrow \\
\text { Pemberdayaan UMKM }\end{array}$ & $0,558^{* *}$ & 2,852 \\
$\begin{array}{l}\text { Dampak Lingkungan } \rightarrow \\
\text { Pemberdayaan UMKM }\end{array}$ & $-0,010^{\mathrm{ns}}$ & 0,087 \\
\hline
\end{tabular}

Sumber: Data Primer, 2020

Keterangan:

*** : Signifikan pada tingkat kesalahan $\alpha(1 \%)(\mathrm{t}$-tabel 2,95$)$

** : Signifikan pada tingkat kesalahan $\alpha(5 \%)(\mathrm{t}$-tabel 2,13$)$

* : Signifikan pada tingkat kesalahan $\alpha(10 \%)(\mathrm{t}$-tabel 1,75$)$

ns : Tidak signifikan

Berdasarkan hasil uji bootstraping PLS diketahui bahwa variabel dampak sosial berpengaruh signifikan pada tingkat kesalahan $(\alpha=10 \%)$ dengan hasil uji statistik yaitu t-statistic lebih besar dari t-tabel $(2,100>1,75)$ sehingga dapat dinyatakan bahwa dampak sosial dari adanya penggunaan apliaksi qasir berpengaruh signifikan dalam pemberdayaan UMKM Mitra. Dampak sosial pemanfaatan aplikasi qasir dapat dirasakan oleh UMKM Mitra melaui proses pengelolaan administrasi usaha menjadi lebih mudah dan teratur, UMKM tidak perlu mencatat transaksi secara manual di buku lagi. Contoh lain yaitu pengelolaan data produk pada aplikasi qasir dapat dilakukan, sehingga pemilik usaha dapat mengetahui keuntungan atau kerugian dari penjualan produk secara langsung. Hal di atas sejalan dengan penelitian Srirejeki, (2016) yang menyatakan bahwa dengan memanfaatkan fiturfitur murah dan gratis dalam aplikasi digital ataupun media sosial dapat membantu UMKM untuk menyebarkan informasi mengenai produk kepada pelanggan.

Selain itu, jika dilihat pada Tabel 7. dapat diketahui pada tingkat kesalahan $(\alpha=5 \%)$ variabel dampak ekonomi berpengaruh signifikan terhadap pemberdayaan UMKM yaitu t-statistic lebih besar dari t-tabel $(2,852>2,13)$. Hal ini menunjukkan 
bahwa pemanfaatan aplikasi qasir memberikan dampak ekonomi yaitu pengeluaran biaya untuk pembelian ATK menjadi berkurang. Variabel dampak ekonomi memiliki koefisien jalur yang lebih tinggi dibanding dampak sosial dan lingkungan, yang berarti bahwa untuk meningkatkan pemberdayaan UMKM dapat dilakukan dengan meningkatkan dampak ekonomi kepada UMKM penerima manfaat dari adanya program aplikasi digital ramah lingkungan ini. Hasil penelitian ini didukung oleh Rustono, (2013) yang menyatakan bahwa aplikasi digital sebagai salah metode pemanfaatan teknologi informasi memiliki penngaruh terhadap kinerja usaha dengan kata lain dapat memberdayaan UMKM.

Sementara itu, uji statistik pada tingkat kesalahan $(\alpha=10 \%)$ menunjukan bahwa variabel dampak lingkungan tidak berpengaruh signifikan terhadap pemberdayaan UMKM yang dilihat dari nilai t-statistic yang lebih kecil daripada t-tabel $(0,087<1,75)$. Hal ini terjadi karena dampak lingkungan belum memberikan banyak manfaat secara langsung terkait pengeloaan administrasi usaha dari UMKM. Namun dengan adanya pemanfaatan aplikasi qasir penggunaan kertas oleh UMKM menjadi berkurang sehingga dapat menyebabkan lingkungan menjadi bersih karena kurangnya limbah kertas yang digunakan.

\section{Kesimpulan}

Berdasarkan analisis statistik dampak sosial, ekonomi, dan lingkungan setelah menggunakan aplikasi qasir, diketahui bahwa nilai rerata tertinggi adalah dampak ekonomi yaitu 3,94 dan standar deviasi 0,70. Variabel dampak sosial dan dampak ekonomi berpengaruh signifikan terhadap pemberdayaan UMKM Mitra, sedangkan variabel dampak lingkungan tidak berpengaruh signifikan terhadap pemberdayaan UMKM Mitra melalui aplikasi qasir.

Untuk melengkapi hasil penelitian ini, perlu adanya penelitian selanjutnya yang berkaitan dengan kepuasan pelaku usaha (UMKM) terhadap penggunaan aplikasi digital qasir pada usahanya sebagai bentuk evaluasi pada program yang telah dijalankan.

\section{Ucapan Terima Kasih}

Penulis mengucapkan terima kasih kepada Community Empowerment dept,. PT. Kaltim Prima Coal atas dukungan, bantuan serta telah memfasilitasi dalam penelitian ini sebagai bentuk kerjasama antara PT KPC dengan Sekolah Tinggi Pertanian Kutai Timur.

\section{Referensi}

Amelia, M. N., Prasetyo, Y. E., \& Maharani, I. (2017). E-UMKM: Aplikasi Pemasaran Produk
UMKM Berbasis Android Sebagai Strategi Meningkatkan Perekonomian Indonesia. Prosiding SNATIF, 11-16.

Barus, D. S., Marliyah, \& Sugianto. (2020). Strategi Pengembangan Digital Entrepreneurship Usaha Mikro Kecil Menengah (UMKM) Dengan Menggunakan Model Pentahelix. Jurnal Eknis, 9(1), 190-205.

Databoks. (2020). Pemerintah Beri Stimulus. Berapa jumlah UMKM di Indonesia? Retrieved from https://databoks.katadata.co.id/datapublish/2020 /04/08/pemerintah-beri-stimulus-berapa-jumlahumkm-di-indonesia

Ghozali, I., \& Latan, H. (2015). Partial Least Squares: Konsep, Teknik dan Aplikasi menggunakan Program Smart PLS 3.0. Semarang: Badan Penerbit UNDIP.

Kurniawan, F. D., \& Fauziah, L. (2014). Pemberdayaan Usaha Mikro Kecil dan Menengah (UMKM) dalanm Penanggulangan Kemiskinan. Jurnal Kebijakan Dan Manajemen Publik, 2(2), 165-176.

Lubis, T. A., \& Junaidi, J. (2016). Pemanfaatan Teknologi Informasi Pada Usaha Mikro Kecil Dan Menengah Di Kota Jambi. Jurnal Perspektif Pembiayaan Dan Pembangunan Daerah, 3(3), 163-174.

Purwana, D., Rahmi, R., \& Aditya, S. (2017). Pemanfaatan Digital Marketing Bagi Usaha Mikro, Kecil, Dan Menengah (UMKM) Di Kelurahan Malaka Sari, Duren Sawit. Jurnal Pemberdayaan Masyarakat Madani (JPMM), 1(1), $1-17$. https://doi.org/10.21009/jpmm.001.1.01

Rahadhini, M. (2012). Pemberdayaan UMKM Melalui Pusat Komunikasi Bisnis Berbasis WEB (E-Commerce). Jurnal Ekonomi Dan Kewirausahaan, 12(1), 12-21.

Rustono. (2013). Pemanfaatan Teknologi Informasi dan Pengaruhnya Terhadap Kinerja Usaha Kelompok Bisnis Entrepreneur. Tersedia: Http://Admisibisnis.Blogspot.Com/2013/12/Pem anfaatan-Teknologi-Informasi-Dan.Html.

Satori, Suryatna, Y., \& Syatori. (2017). Pemberdayaan Usaha Mikro, Kecil, dan Menengah (UMKM) Melalui Program CSR PT INDOCEMENT (Studi Kasus Di Blok Kebon Gedang Desa Ciwaringin Kecamatan Ciwaringin Kabupaten Cirebon). Empower: Jurnal Pengembangan Masyarakat Islam, 1(2).

Slamet, R., Nainggolan, B., Roessobiyatno, R., Ramdani, H., Hendriyanto, A., \& Ilma, L. L. 
(2017). Strategi Pengembangan UKM Digital Dalam Menghadapi Era Pasar Bebas. Jurnal Manajemen Indonesia, 16(2), 136. https://doi.org/10.25124/jmi.v16i2.319

Srirejeki, K. (2016). Analisis Manfaat Media Sosial dalam Pemberdayaan Usaha Mikro Kecil dan Menengah (UMKM). Jurnal Masyarakat Telematika Dan Informasi, 7(1), 57-68.

Sugiyono. (2014). Metode Penelitian Pendidikan Pendekatan Kuantitatif, Kualitatif, dan R\&D. Bandung: Alfabeta.

Sunariani, N. N., Suryadinata, A. O., \& Mahaputra, I. I. R. (2017). Pemberdayaan Usaha Mikro kecil dan Menengah (UMKM) melalui Program Binaan di Provinsi Bali. Jurnal Ilmiah Manajemen Dan Bisnis, 2(1), 1-20.
Suprihadi, Wijaya, A. F., \& Utami, B. S. (2016). Pemberdayaan UMKM Berbasis Teknologi Informasi Dan Komunikasi Kabupaten Kendal Menuju Pasar Global. Jurnal Informatika, 12(1), 51-66. https://doi.org/10.21460/inf.2016.121.422

Undang-Undang. Undang-Undang Nomor 20 Tahun 2008 tentang Usaha Mikro Kecil dan Menengah. (2008). 